\title{
Emerging use of Stem Cell Transplants for Systemic Sclerosis
}

Author:

Sheryl Mascarenhas, MD, Assistant Professor of Medicine

Department of Internal Medicine

Division of Rheumatology and Immunology

The Ohio State University

E-mail:

Sheryl.mascarenhas@osumc.edu

\begin{abstract}
Over the last 20 years, stem cell transplant (SCT) has shown promising results in a variety of autoimmune rheumatologic disorders. Of these conditions, systemic sclerosis (SSc) has garnered the most attention given the limited alternative options for advanced disease. Several early studies and now several randomized controlled trials have demonstrated improved skin, lung, and vascular outcomes. However, complications associated with the immunoablating steps in the transplant process have led to cardiotoxicity, infections, and death in some transplant recipients. Growing efforts are being made to examine how to optimize the transplant process to improve safety but retain efficacy.
\end{abstract}

Keywords: stem cell transplant; systemic sclerosis. 


\section{Introduction}

The advancement of stem cell transplant (SCT) for autoimmune rheumatologic diseases has continued to be an area of investigation. Among the rheumatologic disorders, systemic sclerosis (SSc) remains the most widely studied. This continued pursuit of SCT in $\mathrm{SSc}$ is driven largely due to the limited effective treatment options available for this condition.

SSc is a fibrosing multisystem disorder that can affect the skin, lungs, gastrointestinal tract and pulmonary vasculature [1-3]. There are 2 major categories, limited and diffuse, distinguished by the extent of skin involvement. Diffuse SSc is associated with higher incidence of heart, lung, and kidney involvement and carries a 5-10\% per year mortality risk $[4,5]$. For patients with such severe, refractory autoimmune conditions SCT has emerged as a treatment with great promise.

\footnotetext{
SCT essentially works by expunging the disease causing proinflammatory immune system and later repopulating it with harvested stem cells; it has been likened to a resetting of the
}

immune system [6,7]. There are several steps in the transplant process. Cells must first be mobilized often with cyclophosphamide and growth-colony stimulating factor (G-CSF). The mobilized cells are harvested and the recipient then generally undergoes an immunoablative conditioning regimen, often including cyclophosphamide and anti-thymocyte globulin (ATG), before the cells are infused.

The majority of SCTs in scleroderma utilize hematopoietic stem cells, which are capable of differentiating into cells belonging to both myeloid and lymphoid lineages [8]. Hematopoietic stem cell transplants (HSCTs) are mobilized from either the patient (autologous) or from another individual, typically an HLA-identical sibling or unrelated donor (allogenic). Prior to transplantation, the harvested cells often may be manipulated to deplete or select for certain cell types. CD34+ selection is often employed to select for hematopoietic stem cells, thus eliminating T cells [9]. 


\section{Use of Hematopoietic stem cell}

\section{transplant in Systemic Sclerosis}

The European Group for Blood and Marrow Transplantation

(EBMT) Autoimmune Disease Working Party (ADWP) has maintained a database on patients receiving HSCT in Europe. As of 2015, 433 patients with SSc have been registered [10]. Early data yielded positive results with patients achieving reductions in disease severity. In 2007, a pilot phase II single-arm study with high dose immunosuppressive therapy and HSCT was performed in 34 patients with poor prognosis SSc. Patients demonstrated a significant decrease in modified Rodnan skin scores (mRSS) but there was a high rate of treatment related mortality (TRM) at 23\% [11]. Also in that year, a phase I study with 10 SSc patients reported improved mRSS and 90\% survival and $70 \%$ progression free survival at a mean 25.5 months follow-up [12]. Later in 2012 a cohort study of 26 SSc patients demonstrated significant improvements in mRSS and mean inspiratory vital capacity [13]. These studies helped set the framework for several randomized clinical trials (RTCs) that have been done or are currently ongoing in the field of HSCT and SSc. Table 1 illustrates these studies and their transplant regimens.

The phase II American Scleroderma Stem Cell versus Immune Suppression Trial (ASSIST) was the first of the 3 studies; it was published in 2011. This was a small sized study restricted to patients younger than 60 years of age with either interstitial lung disease or those with other organ involvement who had mRSS $>14.10$ patients were randomized to autologous HSCT with cyclophosphamide and ATG and 9 were randomized to monthly intravenous cyclophosphamide. At 12 months, none of the monthly cyclophosphamide patients improved, however all of the HSCT patients improved achieving primary endpoints defined as an improvement of $>25 \%$ in the mRSS or $>10 \%$ improvement in their forced vital capacity. There was no treatment related mortality (TRM) reported. [14•].

The larger phase III Autologous Stem Cell Transplantation International Scleroderma (ASTIS) trial was published in 2015. It included patients from the EBMT; it was a 2 year multi-centre RCT. 79 patients were randomized to 
autologous HSCT following high dose cyclophosphamide and ATG for conditioning with CD34+ HSC selection and 77 were randomized to receive high dose monthly intravenous cyclophosphamide. The HSCT arm had a significantly prolonged event-free survival and overall survival over a median 5.8 year follow-up. Secondary endpoints demonstrated improvement in the HSCT group with regard to quality of life, mRSS, pulmonary function, particularly forced vital capacity and total lung capacity $[15 \bullet \bullet]$.

Unlike ASSIST, this larger study did report several TRMs including 19 deaths and 3 irreversible organ failures in the HSCT group as well as 23 deaths and 8 irreversible organ failures in the cyclophosphamide group. Of note, TRM was highest in the early stages of followup in the autologous HSCT group. However long-term event-free and overall survival rates were higher in the autologous HSCT than in the control group [15••]

The third RCT is a large ongoing prospective clinical trial in North America evaluating HSCT in SSc, the Scleroderma Cyclophosphamide or Transplant (SCOT) trial. The SCOT trial is a phase II/III randomized study comparing myeloablative (total body irradiation and cyclophosphamide) autologous HSCT versus monthly cyclophosphamide with similar endpoints as the ASTIS trial [16]. The recruitment phase for the SCOT trial is now complete, however results have not yet been released [17].

\section{Use of Stem Cell Transplant for} localized manifestations of Scleroderma

In the last several years innovative use SCT for non-life threatening SSc has emerged with particular applications for cutaneous and peripheral vascular phenomena. Several of these small studies have looked at the use of multipotent adipose derived stem cells (ADSC), which possess increased expression of vascular endothelial growth factor, basic fibroblast growth factor and interleukin-6 and can also secrete anti-inflammatory soluble factors including interleukin-10, interferon- $\gamma$, and transforming growth factor- $\beta[18,19]$.

For these non-life threatening manifestations, the stem cells have been transplanted directly into subcutaneous or ischemic tissues. This local transplant 
technique does not necessitate the mobilization or immunoablative steps associated with more standard HSCT regimens. Table 2 highlights some of the recent studies evaluating SCT on local scleroderma. These have yielded improved skin thickening, digital ulcers, and pain [20-23]. Additional larger studies would be needed to draw more firm conclusions on the benefits of localized delivery of stem cells.

\section{Cardiopulmonary Risks related}

\section{to Transplant Related Mortality}

One of the critical questions to arise from the past 20 years of SCT in SSc is how to identify risk factors related to TRM. TRM is defined by the Milan consensus as death within the first 3 months of transplant [24]. Early cases of HSCT in SSc revealed higher cardiac related mortality which has spawned early recommendations on cardiac prescreening prior to SCT [25]. In 2012 the EMBT released updated guidelines on SCT for autoimmune diseases; several pre-screening HSCT criteria were outlined to better focus patient selection. Table 3 summarizes these organ specific guidelines. For SSc patients advanced cardiac disease defined as a left ventricular ejection fraction $<50 \%$, uncontrolled ventricular arrhythmias, pericardial effusions $>1 \mathrm{~cm}$, were exclusion cardiac criteria. Respiratory disease including diffusing capacity of the lung for carbon monoxide (DLCO) $<40 \%$ predicted, mean pulmonary artery pressure $>50 \mathrm{mmHg}$, and renal insufficiency defined as a creatinine clearance $<40 \mathrm{ml} / \mathrm{min}$ per $\mathrm{m}^{2}$, were also criteria for exclusion. Pre-screening testing for infections was also addressed in the guidelines. It included Herpes simplex virus (HSV), Varicella zoster virus (VZV), Epstein - Barr virus (EBV), human immunodeficiency virus (HIV), human T-lymphotropic virus type 1 and 2, hepatitis viruses and toxoplasmosis, and any other infection screening appropriate for the geographical location. [26••].

Outside of the EBMT cardiac guidelines, other recommendations have been proposed including pre-screening echocardiography with tissue Doppler and quantitative assessment of right ventricular function (e.g. tricuspid annular plane systolic excursion) right heart catheterization with fluid challenge, cardiac magnetic resonance imaging with 
gadolinium contrast (including T1 mapping for assessment of diffuse myocardial fibrosis) [27-29].

Recent data support the pulmonary criteria by the EMBT. In a retrospective study over a 5 year period, N Del Papa et al. asserted that lower TRM may have potentially been attributed to excluding patients with a DLCO below 50\% of predicted value in the retrospective study of 18 patients with SSc [30]. Smoking history is another proposed exclusion criteria. In post hoc analysis of the ASTIS trial 7 of the 8 cases of TRM in HSCT arm involved patients who had a smoking history $[15,31]$.

\section{Transplant Protocol Risks} related to Transplant Related Mortality

In addition to evaluating risks associated with patient selection, another area of investigation that can affect TRM involves the specific transplant protocols. There are potential variances at every step of the transplant process, each of which may have differing impacts on TRM or serious adverse effects. The first area to consider is the donor source of the cell. Typically transplants are done with autologous cells; allogenic cells have fallen out of favour given the risks of graft versus host disease [31]. However, emerging use of other cell sources including adipose derived cells for nonlife threatening scleroderma would also likely have an impact on risk of TRM.

Mobilization is another step in the transplant process that can vary. Blank N, et al performed a retrospective comparison of chemotherapy with cyclophosphamide 2 doses of $2 \mathrm{~g} / \mathrm{m}^{2}$ and 1 dose of $2 \mathrm{~g} / \mathrm{m}^{2}$ and found comparable mobilization results in patients with several autoimmune diseases including 15 patients with SSc [32]. This study provides a rationale for potentially lowering cumulative cyclophosphamide dosing.

After cells are mobilized, some protocols call for CD 34+ selection, a process that may delay immune reconstitution and lymphocyte ontogeny $[33,34]$. Cell selection also increases the cost of transplant, reduces the number of stem cells available for infusion, and predisposes the material to potential contamination by handling [35,36]. In 2016, a review of 138 SSc patients found that CD34+ selection did not yield any statistical significance on overall survival. 
Additionally there were no significant differences for progression of SSc or incidence of relapse [37]. In the 2012 EBMT guidelines no significant evidence was felt to support ex-vivo graft manipulation $[26 \bullet \bullet]$.

Conditioning regimens are an emerging area of investigation as well. In a smaller study of 6 patients, lower dose cyclophosphamide $1 \mathrm{~g} / \mathrm{m}^{2}$ along with thiotepa, an alkylating agent with no known cardiotoxicity, demonstrated effectiveness in SSc patients with cardiac involvement [38]. A larger RCT is also recruiting patients. As a follow-up to the initial ASSIST trial, ASSIST II plan to compare the ASSIST I conditioning regimen of cyclophosphamide and rabbit ATG to a less intense regimen of rabbit ATG/cyclophosphamide/Fludarabine. The cyclophosphamide dose will be decreased to $120 \mathrm{mg} / \mathrm{kg}(60 \mathrm{mg} / \mathrm{kg} /$ day x 2) compared to $200 \mathrm{mg} / \mathrm{kg} \quad(50 \mathrm{mg} / \mathrm{kg} /$ day $)$ in the standard regimen used in ASSIST I in efforts to lower cardiotoxic risks [39].

\section{Patient Selection}

SCT should be considered a treatment option for select SSc patients. The 2012 EBMT guidelines recommended autologous HSCT be considered in diffuse SSc patients with disease duration $\leq 5$ years since development of first non-Raynaud's symptoms, have a mRSS $\geq 15$, and have major organ involvement (pulmonary, cardiac, or renal) with evidence of onset or clinically significant worsening in the previous 6 months. Pulmonary criteria were defined as a DLCO $\leq 70 \%$ of predicted plus evidence of interstitial lung disease on a chest radiograph or high resolution computerized tomography scan. Cardiac involvement included second and third-degree atrioventricular block, intra-ventricular conduction disturbance, left axis deviation, atrial or ventricular rhythm disturbance, and pericarditis as defined by $\leq 1 \mathrm{~cm}$ on cardiac ultrasound. Finally, renal was proteinuria $>0.3 \mathrm{~g} / 24 \mathrm{~h}$, without other explanation other than SSc [26••]. Table 4 highlights these characteristics of patients that may be potential candidates for HSCT. Patients deemed appropriate candidates for SCT should be considered for referral to medical centres with expertise and experience in SCT. 


\section{Conclusion}

$\mathrm{SCT}$ in SSc is providing new areas of promise for a condition with otherwise limited treatment options. Large RCTs have now demonstrated significant improvements in organ involvement and survival. Despite positive results, TRM remains a major concern. Prescreening of patients undergoing SCT can lower this risk. Future studies evaluating optimal transplant protocols that will preserve efficacy but lower risks are ongoing. Final results from the SCOT and ASSIST II trials are expected to provide important insights moving forward.

\section{Disclosure}

No potential conflicts of interest relevant to this article were reported. 


\section{References}

Papers of particular interest, published recently, have been highlighted as: - Of importance $\bullet$ Of major importance

1. Prescott RJ, Freemont AJ, Jones CJ, et al. Sequential dermal microvascular and perivascular changes in the development of scleroderma. J Pathol. 1992;166(3):255-63.

2. $\mathrm{Hu} \mathrm{H}$, Stein-Streilein J. Haptenimmune pulmonary interstitial fibrosis (HIPIF) in mice requires both CD4+ and CD8+ T lymphocytes. J Leukoc Biol. 1993;54(5):414-22.

3. Rosa SB, Voltarelli JC, Chies JA, et al. The use of stem cells for the treatment of autoimmune diseases. Braz J Med Biol Res. 2007;40(12):1579-97.

4. Denton CP. Systemic sclerosis: from pathogenesis to targeted therapy. Clin Exp Rheumatol. 2015;33 (4Suppl 92):S3-7.

5. Ioannidis JP, Vlachoyiannopoulos PG, Haidich AB, et al. Mortality in systemic sclerosis: an international meta-analysis of individual patient data. Am J Med.2005;118:2-10

6. Mascarenhas S, Avalos B, \& Ardoin SP, An Update on Stem Cell Transplantation in Autoimmune Rheumatologic Disorders. Curr
Allergy Asthma Rep. 2012;12(6):530540.

7. Sykes M \& Nikolic B. Treatment of severe autoimmune disease by stemcell transplantation. Nature.2005; 435;620-627.

8. DiPersio JF, Micallef IN, Stiff PJ, et al. Phase III Prospective Randomized Double-Blind Placebo-Controlled Trial of Plerixafor Plus Granulocyte Colony-Stimulating Factor Compared with Placebo Plus Granulocyte Colony-Stimulating Factor for Autologous Stem-Cell Mobilization and Transplantation for Patients with Non-Hodgkin's Lymphoma. J Clin Oncol. 2009;27(28):4767-73.

9. Moore J, Brooks P, Milliken S, et al. A pilot randomized trial comparing CD34-selected versus unmanipulated hematopoietic stem cell transplantation for severe refractory rheumatoid arthritis. Arthritis Rheum. 2002;46(9):2301-9.

10. Kelsy PJ, Oliveira MC, Badogolio M, et al. Haematopoietic stem cell transplantation in autoimmune diseases: From basic science to 
clinical practice. Curr Res Transl Med. 2016;64(2):71-82.

11. Nash RA, McSweeney PA, Crofford LJ, et al. High-dose immunosuppressive therapy and autologous hematopoietic cell transplantation for severe systemic sclerosis: long-term follow-up of the US multicenter pilot study. Blood. 2007;110-1388-96

12. Oyama Y, Barr WG, Statkute L, et al. Autologous non-myeloablative hematopoietic stem cell transplantation in patients with systemic sclerosis. Bone Marrow Transplant. 2007;40(6):549-55.

13. Henes JC, Schmalzing M, Vogel W, et al. Optimization of autologous stem cell transplantation for systemic sclerosis: a single-center long-term experience in 26 patients with severe organ manifestations. J Rheumatol. $2012 ; 39: 269-275$

14. - Burt RK, Shah SJ, Dill K, et al. Autologous non-myeloablative haematopoietic stem-cell transplantation compared with pulse cyclophosphamide once per month for systemic sclerosis (ASSIST): an openlabel, randomized phase 2 trial. Lancet. 2011;378(9790):498-506. First randomized controlled trial regarding HSCT use in systemic sclerosis.

15. ••van Larr JM, Farge D, Sont JK, et al. Autologous hematopoietic stem cell transplantation versus intravenous pulse cyclophosphamide in diffuse cutaneous systemic sclerosis: a randomized clinical trial. JAMA.2014;311:2490-8. Largest published randomized controlled trial regarding HSCT use in systemic sclerosis to date.

16. Naraghi K, van Laar JM. Update on stem cell transplantation for systemic sclerosis: recent trial results. Curr Rheumatol Rep. 2013;15:326

17. Ramaswamy S, Jain S, \& Ravindran V. Hematopoietic stem cell transplantation for autoimmune rheumatic diseases. World J Transplant. 2016;6(1):199-205.

18. Kapur SK and Katz AJ. Review of the adipose derived stem cell secretome. Biocheimi. 2013;95:2222-8.

19. Leto Barone AA, Khalifian S, Lee WP, et al. Immunomodulatory effects of adipose-derived stem cells: fact or fiction?. Biomed Res Int. 2013; 2013:383685.

20. Del Papa N, Di Luca G, Sambataro D, et al. Regional implantation of 
autologous adipose tissue-derived cells induces a prompt healing of long-lasting indolent digital ulcers in patients with systemic sclerosis. Cell Transplant. 2015;24(11):2297-35.

21. Scuderi N, Ceccarelli S, Onesti MG, et al. Human adipose-derived stromal cells for cell-based therapies in the treatment of systemic sclerosis. Cell Transplant. 2013;22:779-95.

22. Granel B, Daumas A, Jouve E, et al. Safety, tolerability and potential efficacy of injection of autologous adipose-derived stromal vascular fraction in the fingers of patients with systemic sclerosis: an open-label phase I trial. Ann Rheum Dis. 2015;74(12):2175-2182.

23. Takagi G, Miyamoto M, Tara S, et al. Therapeutic vascular angiogenesis for intractable macroangiopathy-related digital ulcer in patients with systemic sclerosis: a pilot study Rheumatology (2014) 53 (5): 854-859

24. Song X, Lv HY, Sun LX, et al. Autologous stem cell transplantation for systemic lupus erythematosus: report of efficacy and safety at 7 years of follow-up in 17 patients. Transplant Proc. 2011;43(5):1924-7.
25. Saccardi R, Tyndall A, Coghlan G, et al. Consensus statement concerning cardiotoxicity occurring during haematopoietic stem cell transplantation in the treatment of autoimmune disease, with special reference to systemic sclerosis and multiple sclerosis. Bone Marrow Transplant. 2004;34(10):877-81.

26. •-Snowden JA, Saccardi R, Allez M, et al. Haematopoietic SCT in severe autoimmune diseases: updated guidelines of the European Group for Blood and Marrow Transplantation. Bone Marrow Transplantation. 2012;47:770-90. Most recent society guidelines regarding patient selection and transplant processes for stem cell transplants in autoimmune diseases.

27. van Laar JM, Naraghi K, Tyndall A. Haematopoietic stem cell transplantation for poor-prognosis systemic sclerosis. Rheumatology 2015; 54: 2126-2133.

28. Burt RK, Shah SJ, Gheorghiade M et al. Hematopoietic stem cell transplantation for systemic sclerosis: if you are confused, remember: "it is a matter of the heart". Journal of Rheumatology. 2012;39:206-9.

29. Burt RK, Oliveira MC, \& Shah SJ. Cardiac Assessment Before Stem Cell 
Transplantation for Systemic Sclerosis. JAMA. 2014;12(17):1803.

30. N Del Papa, Onida F, Zaccara E, et al. Autologous hematopoietic stem cell transplantation has better outcome than conventional therapies in patients with rapidly progressive systemic sclerosis. Bone Marrow Transplantatio. advance online publication 22 August 2016; doi: 10.1038/bmt.2016.211

31. van Laar JM, Naraghi K, \& Tyndall A. Haematopoietic stem cell transplantation for poor-prognosis systemic sclerosis. Rheumatology (Oxford). 2015;54(12):2126-33.

32. Blank N, Lisenko K, Pavel P, et al. Low-dose cyclophosphamide effectively mobilizes peripheral blood stem cells in patients with autoimmune disease. Eur J Haematol. 2016;97(1):78-82.

33. Martínez C, Urbano-Ispizua A, Rozman C, et al. Immune reconstitution following allogeneic peripheral blood progenitor cell transplantation: comparison of recipients of positive CD34+ selected grafts with recipients of unmanipulated grafts. Exp Hematol. 1999;27:561-8.
34. Marek A, Stern M, Chalandon Y, et al. The impact of T-cell depletion techniques on the outcome after haploidentical hematopoietic SCT. Bone Marrow Transplant 2014; 49:55-61.

35. Slaper-Cortenbach IC, Wijngaardendu Bois MJ, de Vries-van Rossen A, et al. The depletion of $\mathrm{T}$ cells from haematopoietic stem cell transplants. Rheumatology

(Oxford) 1999;38(8):751-754.

36. Webb IJ, Coral FS, Andersen JW, Elias AD, Finberg RW, et al. Sources and sequelae of bacterial contamination of hematopoietic stem cell components: implications for the safety of hematotherapy and graft engineering. Transfusion. 1996;36(9):782-788.

37. Oliveira MC, Labopin $\mathrm{M}$, Henes $\mathrm{J}$, et al. Does ex vivo CD34+ positive selection influence outcome after autologous hematopoietic stem cell transplantation in systemic sclerosis patients?. Bone Marrow Transplant. 2016;51(4):501.5.

38. Henes JC, Koetter I, Horger M, et al. Autologous stem cell transplantation with thiotepa-based conditioning in patients with systemic sclerosis and 
cardiac manifestations. Rheumatology

(Oxford). 2014;53(5):919-22.

39. Autologous Stem Cell Systemic Sclerosis Immune Suppression Trial (DIScl2011). Available at https://clinicaltrials.gov/show/NCT01 445821. Accessed August 2016
40. Craciunescu OI, Steffey BA, Kelsey $\mathrm{CR}$, et al. Renal shielding and dosimetry for patients with severe systemic sclerosis receiving immunoablation with total body irradiation in the scleroderma: cyclophosphamide or transplant trial. Int $\mathrm{J}$ Radiat Oncol Biol Phys. 2011;79(4):1248-55. 
Table 1. Randomized Controlled Trials of Hematopoietic Stem Cell Transplant in Systemic Sclerosis

\begin{tabular}{|c|c|c|c|c|}
\hline & ASSIST I [14•] & ASTIS $[15 \bullet \bullet]$ & SCOT $[16,40]$ & ASSIST II [39] \\
\hline Control & Monthly IV CYC & Monthly IV CYC & Monthly IV CYC & Monthly IV CYC \\
\hline regimen & $\begin{array}{l}1 \mathrm{~g} / \mathrm{m}^{2} \times 6 \text { doses } \\
\text { doses }\end{array}$ & $\begin{array}{l}750 \mathrm{mg} / \mathrm{m}^{2} \times 12 \\
\text { doses }\end{array}$ & $\begin{array}{l}750 \mathrm{mg} / \mathrm{m}^{2} \times 12 \\
\text { doses }\end{array}$ & $\begin{array}{l}1 \mathrm{~g} / \mathrm{m}^{2} \times 6 \\
\text { doses }\end{array}$ \\
\hline
\end{tabular}

Test Regimen

\begin{tabular}{|c|c|c|c|c|}
\hline Mobilization & $\begin{array}{l}\text { CYC } 2 \mathrm{~g} / \mathrm{m}^{2}+\mathrm{G}-\mathrm{CSF} \\
10 \mu \mathrm{g} / \mathrm{kg}\end{array}$ & $\mathrm{CYC} 4 \mathrm{~g} / \mathrm{m}^{2}+\mathrm{G}-\mathrm{CSF}$ & $\mathrm{CYC} 4 \mathrm{~g} / \mathrm{m}^{2}+\mathrm{G}-\mathrm{CSF}$ & $\begin{array}{l}\text { CYC } 2 \mathrm{~g} / \mathrm{m}^{2}+ \\
\text { G-CSF } 10 \mu \mathrm{g} / \mathrm{kg}\end{array}$ \\
\hline Conditioning & $\begin{array}{l}\text { CYC } 200 \mathrm{mg} / \mathrm{kg}+ \\
\text { Rabbit ATG 0.5-1.5 } \\
\mathrm{mg} / \mathrm{kg} \text { with IV MP } \\
\text { 1,000mg }\end{array}$ & $\begin{array}{l}\text { CYC } 200 \mathrm{mg} / \mathrm{kg}+ \\
\text { rabbit ATG } 75 \mathrm{mg} / \mathrm{kg}\end{array}$ & $\begin{array}{l}800 \mathrm{cGY} \text { TBI (in two } \\
200 \mathrm{cGY} \text { fractions BID) } \\
+ \text { CYC } 120 \mathrm{mg} / \mathrm{kg}+ \\
\text { equine ATG }\end{array}$ & $\begin{array}{l}\text { CYC } 120 \mathrm{mg} / \mathrm{kg} \\
\text { + rabbit ATG + } \\
\text { Fludarabine }\end{array}$ \\
\hline $\begin{array}{l}\text { raft } \\
\text { Ianipulation }\end{array}$ & none & CD34+ selection & CD34+ selection & none \\
\hline
\end{tabular}

IV CYC=intravenous cyclophosphamide, G-CSF=Growth-colony stimulating factor, $A T G=$ anti-thymocyte globulin, $M P=$ methylprednisolone 
Medical Research Archives, Vol. 4, Issue 6, October 2016

Emerging use of Stem Cell Transplants for Systemic Sclerosis

Table 2. Recent Studies Regarding Local Applications of Stem Cells for Localized Scleroderma Features

\begin{tabular}{|c|c|c|c|c|}
\hline Study [Reference] & Patients & SCT & Inclusion features & Results \\
\hline Del Papa N, et al. [20] & 15 & autoADSC & $\begin{array}{l}\text { SSc related digital } \\
\text { ulcers }\end{array}$ & $\begin{array}{l}\text { Improved digital ulcers, } \\
\text { pain }\end{array}$ \\
\hline Scuderi N, et al. [21] & 6 & autoADSC & $\begin{array}{l}\text { localized scleroderma } \\
\text { (linear and plaque } \\
\text { scleroderma, } \\
\text { Generalized morphea) }\end{array}$ & $\begin{array}{l}\text { Improved skin exams, } \\
\text { regression of } \\
\text { dyschromia, arrest of } \\
\text { local disease } \\
\text { progression }\end{array}$ \\
\hline Granel B, et al. [22] & 12 & autoSVF & $\begin{array}{l}\text { SSc with CHFS score } \\
>20 / 90\end{array}$ & $\begin{array}{l}\text { Improved CHFS score, } \\
\text { mRSS, RCS }\end{array}$ \\
\hline Takagi G, et al. [23] & 40 & autoBMMC & $\begin{array}{l}\text { SSc with digital ulcer or } \\
\text { gangrene }\end{array}$ & $\begin{array}{l}\text { Decreased pain, } \\
\text { improved } \mathrm{TcPO}_{2}\end{array}$ \\
\hline
\end{tabular}

Auto= autologous, $A D S C=$ adipose derived stem cells, $S S C=$ systemic sclerosis, SVF= adipose-derived stromal vascular fraction, CHFS=Cochin hand function scale, $m R S S=$ modified Rodnan skin score, RCS=Raynaud condition score, $B M M C=$ bone marrow mononuclear cells, $\mathrm{TCPO}_{2=}$ transcutaneous oxygen tension 
Medical Research Archives, Vol. 4, Issue 6, October 2016

Emerging use of Stem Cell Transplants for Systemic Sclerosis

Table 3. Organ Specific Exclusion Criteria for HSCT in Systemic Sclerosis Patients according to the 2012 European Group for Blood and Marrow Transplantation Guidelines [26••]

Exclusion Criteria

Cardiac Left ventricular ejection fraction $<50 \%$

Uncontrolled ventricular arrhythmias

Pericardial effusions $>1 \mathrm{~cm}$

Pulmonary Diffusing capacity of the lung for carbon monoxide (DLCO) $<40 \%$ predicted,

Mean pulmonary artery pressure $>50 \mathrm{mmHg}$

Renal Creatinine clearance $<40 \mathrm{ml} / \mathrm{min}$ per $\mathrm{m}^{2}$ 
Medical Research Archives, Vol. 4, Issue 6, October 2016

Emerging use of Stem Cell Transplants for Systemic Sclerosis

Table 4. Characteristics of Potential Candidates for HSCT according to the 2012 European Group for Blood and Marrow Transplantation Guidelines [26••]

- Diffuse SSC

- Disease Duration $\leq 5$ years since development of first non-Raynaud's symptoms

- $\quad m R S S \geq 15$

- Any of the following major organ involvement

- Pulmonary

- $\quad$ DLCO $\leq 70 \%$ of predicted

and

- ILD on a imaging

- Cardiac

- Second and third-degree atrioventricular block

- Intra-ventricular conduction disturbance

- Left axis deviation

- Atrial or ventricular rhythm disturbance

- Pericarditis $\leq 1 \mathrm{~cm}$ on cardiac ultrasound

- Renal

- Proteinuria $>0.3 \mathrm{~g} / 24 \mathrm{~h}$

- Disease onset or clinically significant worsening in previous 6 months

$\mathrm{SSc}=$ systemic sclerosis, mRSS= modified Rodnan Skin Score, $D L C O=$ diffusing capacity of the lung for carbon monoxide, ILD= interstitial lung disease. 